Jurnal Informatika dan Rekayasa Perangkat Lunak (JATIKA)
Vol. 1, No. 1, June 2020, page-page. 43-50

\title{
RANCANG BANGUN APLIKASI PRESENSI SMS GATEWAY BERBASIS WEB DENGAN FRAMEWORK CODEIGNITER PADA SMKN 1 TRIMURJO
}

\author{
Yanti Wulandari ${ }^{1}$, Heni Sulistiani ${ }^{2}$ \\ S1 Informatika, Universitas Teknokrat Indonesia ${ }^{1}$ \\ D3 Sistem Informasi Akuntansi, Universitas Teknokrat Indonesia ${ }^{2}$ \\ yantiwulan2406@gmail.com¹, henisulistiani@teknokrat.ac.id ${ }^{2}$
}

Received: (Mei 2020)Accepted: (Mei 2020) Published: (Juni 2020)

\begin{abstract}
Trimurjo Vocational School 1 still uses a manual attendance system in which subject teachers must call the name of the student when starting the class. The school has rules for students who do not attend school during class time and will be informed to parents when they have passed three warnings from the school. the presence system that is currently running is still manual, namely the teacher must check students one by one to ensure that students are present. In addition, another obstacle is lack of communication and information between the school and parents. This can cause students to lie to parents that by reporting being in teaching and learning activities but in reality these students go to play with their friends. This study aims to produce a web-based presence system integrated with the SMS Gateway at Trimurjo Vocational High School 1. With SMS Gateway on the system, the system will automatically notify parents of students about the absence of students at school. Through research and information systems at SMK 1 Trimurjo, the results are obtained that the utilization of the presence of the presence information system can provide solutions in the presence process.

Keywords: Information, Presence, SMS Gateway, System, Web.
\end{abstract}

\begin{abstract}
Abstrak
SMKN 1 Trimurjo masih menggunakan sistem presensi manual dimana guru mata pelajaran harus memanggil nama siswa pada saat memulai pelajaran dikelas. Sekolah memiliki aturan bagi siswasiswi yang tidak hadir kesekolah pada jam pelajaran kemudian akan diinformasikan kepada orang tua apabila sudah melewati tiga kali peringatan dari pihak sekolah. sistem presensi yang berjalan saat ini masih secara manual yaitu guru harus melakukan cek terhadap siswa satu persatu untuk memastikan siswa tersebut hadir. Selain itu kendala lain adalah kurang komunikasi serta informasi antara pihak sekolah dengan orang tua. Hal ini dapat mengakibatkan siswa berbohong kepada orang tua bahwa dengan melaporkan sedang berada dalam kegiatan belajar mengajar namun kenyataannya siswa-siswi tersebut pergi bermain bersama teman-temannya. Penelitian ini bertujuan untuk menghasilkan sistem presensi berbasis web terintegrasi dengan SMS Gateway pada SMKN 1 Trimurjo. Dengan SMS Gateway pada sistem maka secara otomatis sistem akan memberikan pemberitahuan kepada orang tua siswa-siswi mengenai ketidakhadiran siswa-siswi di sekolah. Melalui penelitian dan sistem informasi pada SMKN 1 Trimurjo diperoleh hasil bahwa pemanfaatan penerapan sistem informasi presensi ini dapat memberikan solusi dalam proses presensi.
\end{abstract}

Kata Kunci: Informasi, Presensi, SMS Gateway, Sistem, Web.

\section{To cite this article:}

Yanti Wulandari, Heni Sulistiani. (2020).Rancang Bangun Aplikasi Presensi Sms Gateway Berbasis Web Dengan Framework Codeigniter Pada SMKN 1 Trimurjo. Jurnal Informatika dan Rekayasa Perangkat Lunak, Vol(1), 43-50.

\section{PENDAHULUAN}

Sekolah memiliki aturan bagi siswa-siswi yang tidak hadir ke sekolah pada jam pelajaran kemudian akan diinformasikan kepada orang tua apabila sudah melewati tiga kali peringatan dari pihak sekolah maka orang tua akan mendapat informasi mengenai kelakuan anaknya. Pihak sekolah SMKN 1 Trimurjo biasanya melakukan panggilan pada orang tua melalui surat. Namun, terkadang ketika sekolah menyampaikan informasi mengenai anak ke orang tua melalui surat biasanya tidak sampai kepada orang tua. Sehingga, ini dianggap masih kurang efektif dan kurang efesien serta cara memberikan informasi ke orang tua yang masih belum maksimal. Pencatatan presensi secara manual akan menyebabkan terjadinya penumpukan kertas untuk presensi yang 
berdampak pada mengarsipan (ahmad dan indra, 2016). Selain itu masih diperlukan aktifitas merekap ulang secara manual (damayanti dan sulistiani, 2017) informasi presensi dari setiap kelas sebagai pelaporan kepada pihak kepala sekolah. (Budiman, 2017)

Permasalahan yang ada di SMKN 1 Trimurjo dapat diatasi dengan pengembangan sebuah sistem seperti yang pernah diusulkan membahas tentang presensi di PT. INTI Bandung, sistem mampu melakukan pendataan khusus untuk mencatat kehadiran dan ketidakhadiran karyawan agar keberadaan karyawan dalam melakukan aktifitas kerja tercatat dengan baik. Sistem yang di bangun menggunakan metode desktop application. Hasil dari penelitian ini adalah pengelolaan data presensi dapat dilakukan secara terkomputerisasi dan tersimpan pada basis data. Usulan lainnya yaitu tentang sistem kehadiran siswa pada SMKN 2 Kabupaten Tangerang yangdilakukan (Martono dan Setyawan, 2018). Sistem yang dibuat mampu memantau kehadiran siswa-siswi SMKN 2 Kabupaten Tangerang. Sistem yang dibangun menggunakan metode website. Hasil dari penelitian ini adalah mempermudah dalam pemantauan pelaksanaan sistem kehadiran, serta memudahkan berbagai pihak dalam hal pelaksanaan, perekapan data dan pembuatan laporan yang dapat dilakukan secara online (Rulyana dan Borman, 2014).

\section{TELAAH PUSTAKA}

SMS Gateway

SMS Gateway adalah teknologi mengirim, menerima dan bahkan mengolah sms melalui komputer dan sistem komputerisasi (software). Seperti kita ketahui, pada zaman sekarang, hampir semua individu telah memiliki telepon selular (handphone), bahkan ada individu yang memiliki lebih dari 1 handphone (Afriana, 2015).

\section{Rest API}

Rest (Representational State Transfer) adalah salah satu jenis web service yang menerapkan konsep perpindahan antar state. State disini dapat digambarkan seperti jika browser meminta suatu halaman web, maka sercer akan mengirimkan state halaman web yang sekarang ke browser (Fauziah, 2013).

API (Application Programming Interface) adalah sebuah dokumentasi yang terdiri dari interface, kelas, fungsi, struktur dan sebagainya agar dapat membangun sebuah perangkat lunak. API bisa dikatakan sebagai suatu kode pemrograman penghubung antara aplikasi atau web yang telah kita buat dengan fungsi yang dikerjakan (Raharja dan Aini, 2018).

\section{METODE PENELITIAN}

\section{Sampel}

Sampel yang digunakan dalam penelitian ini adalah 14 orang responden.

\section{Tahapan Penelitian}

Tahapan penelitian merupakan kegiatan penelitian yang dilakukan secara terencana, teratur, dan sistematis untuk mencapai tujuan tertentu. Tahapan penelitian ini juga merupakan pengembangan dari kerangka penelitian 


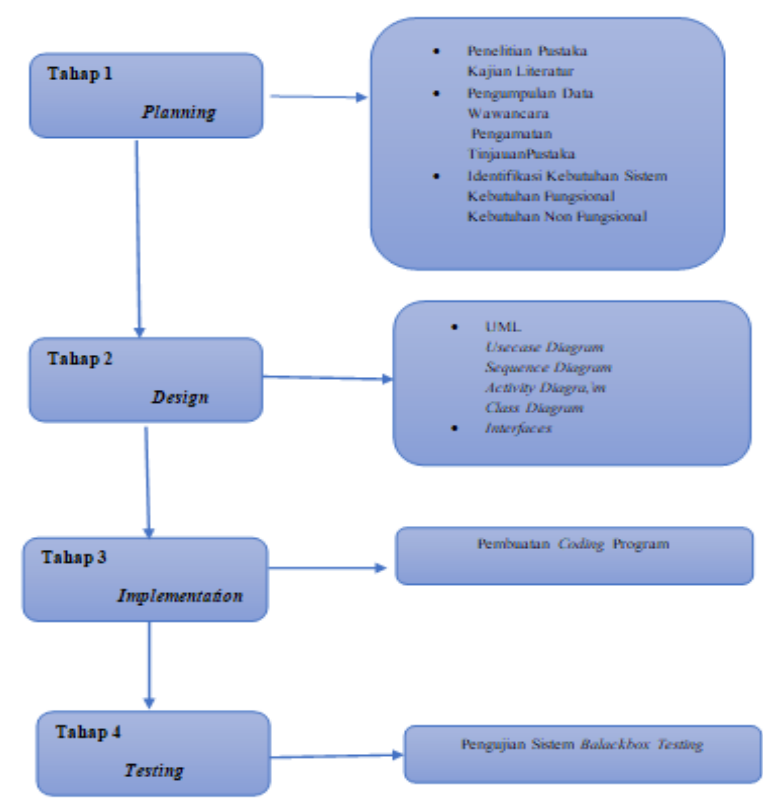

Gambar 1. Tahapan Penelitian

\section{Teknik Pengumpulan Data}

Pengumpulan data yang akan dilakukan pada penelitian ini adalah sebagai berikut:

1. Tinjauan Pustaka (Library Research)

Metode mempelajari kumpulan buku-buku yang dilakukan dengan cara membaca literatur-literatur dan tata bahasa baik yang ada diperpustakaan maupun lainnya yang terkait dengan data yang dibutuhkan, sehingga dapat menunjang proses penelitian.

2. Metode Pengamatan (Observasi)

Mengadakan pengamatan dan mempelajari aplikasi serupa untuk diteliti agar mendapatkan gambaran yang jelas mengenai hal-hal yang dapat dikembangkan pada penelitian.

3. Wawancara (Interview)

Metode Interview yaitu metode pengumpulan data yang dilakukan dengan cara tanya jawab atau wawancara kepada pihak yang berkaitan dengan permasalahan yang dibahas. Pada tahap ini peneliti mewawancarai pihak yang bersangkutan yaitu salah satu guru yang secara langsung menangani proses dan perekapan presensi siswa-siswi pada SMKN 1 Trimurjo. Dari hasil wawancara tersebut kemudian penulis menarik kesimpulan yang menjadi latar belakang masalah dalam penelitian.

\section{Metode Analisis}

Analisis kebutuhan fungsional adalah pernyataan layanan sistem yang harus disediakan, bagaimana sistem bereaksi pada input tertentu dan bagaimana perilaku sistem pada situasi tertentu. Kebutuhan fungsional dari system yang dirancang adalah sebagai berikut. Sistem dapat menginput data siswa-siswi SMKN 1 Trimurjo.

1. Sistem dapat menginput data guru-guru SMKN 1 Trimurjo.

2. Sistem dapat menginput data kelas SMKN 1 Trimurjo.

3. Sistem dapat mencetak laporan presensi SMKN 1 Trimurjo.

4. Sistem dapat melakukan presensi siswa-siswi SMKN 1 Trimurjo.

5. Sistem dapat mengirimkan SMS pemberitahuan ketidakhadiran kepada orang tua siswa-siswi SMKN 1 Trimurjo.

6. Sistem dapat melihat data siswa-siswi SMKN 1 Trimurjo.

7. Sistem dapat mengetahui ketidakhadiran siswa-siswi melalui SMS yang dikirimkan oleh pihak SMKN 1 Trimurjo.

8. Sistem dapat menampilkan laporan presensi siswa-siswi SMKN 1 Trimurjo melalui sistem. 


\section{Usecase Diagram}

Usecasediagram mendeskripsikan sebuah interaksi antara satu atau lebih aktor dengan sistem yang akan dibuat. Usecase digunakan untuk mengetahui fungsi apa saja yang ada didalam sebuah sistem. Berikut adalah rancangan usecasediagram pada aplikasi presensi SMS gateway SMKN 1 Trimurjo.

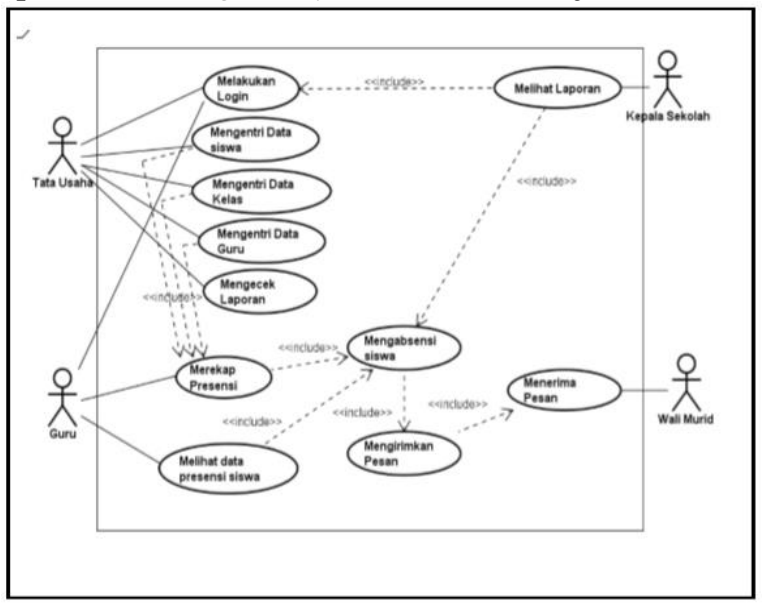

\section{HASIL DAN PEMBAHASAN}

Gambar 2. Usecase Diagram

Pembentukan merupakan pembahasan mengenai penerapan rancangan yang telah dibangun menggunakan bahasa pemprograman dan pembahasan merupakan tahap penjelasan sistem yang selanjutnya dilakukan implementasi, yaitu tahap dimana sistem sudah siap dioperasikan. Tahap penggunaan sistem ini dilakukan setelah penyusunan akhir selesai, kemudian peneliti melaksanakan pelatihan terhadap pengguna dengan memberi pengertian dan pengetahuan yang cukup tentang sistem informasi, posisi dan tugas setiap fungsi. Hal ini dimaksudkan agar user memahami prosedur kerja sistem, dapat mengurangi kesalahan-kesalahan yang timbul yang dapat menghambat kelancaran penggunaan sistem. Sistem yang dibuat ini diharapkan tidak adanya lagi keterlambatan pemberitahuan informasi dan tidak adanya human error.

\section{Penerapan Halaman Login}

Tampilan halaman login untuk sistem dapat di lihat pada gambar berikut

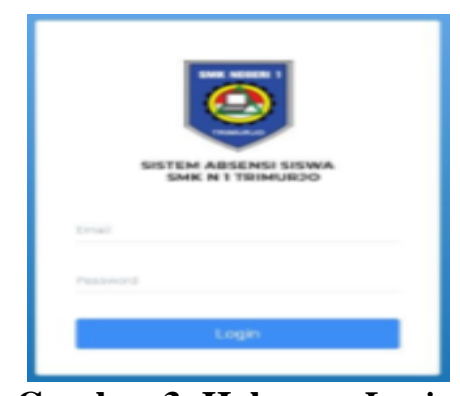

Gambar 3. Halaman Login

\section{Penerapan Halaman Beranda}

Tampilan halaman beranda untuk sistem dapat di lihat pada gambar berikut 


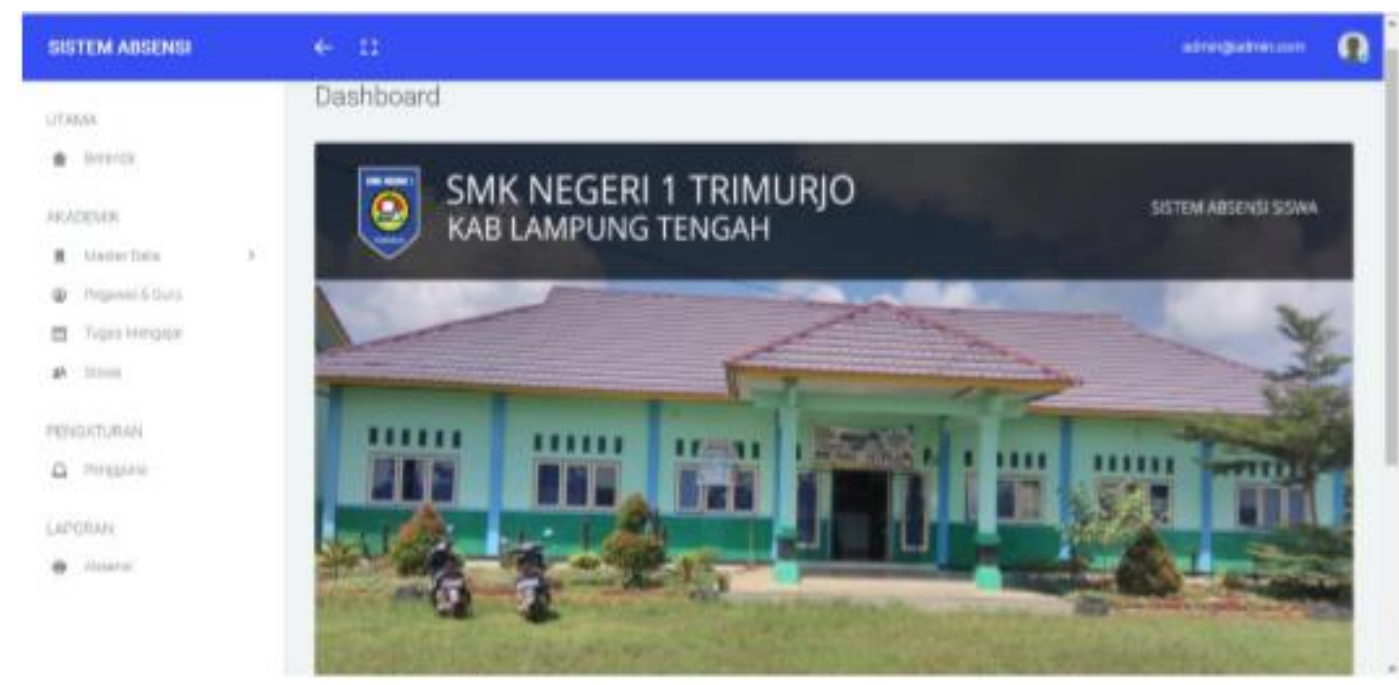

Gambar 4. Halaman Beranda

\section{Pengenalan Halaman Presensi}

Tampilan halaman presensi untuk sistem dapat di lihat pada gambar berikut

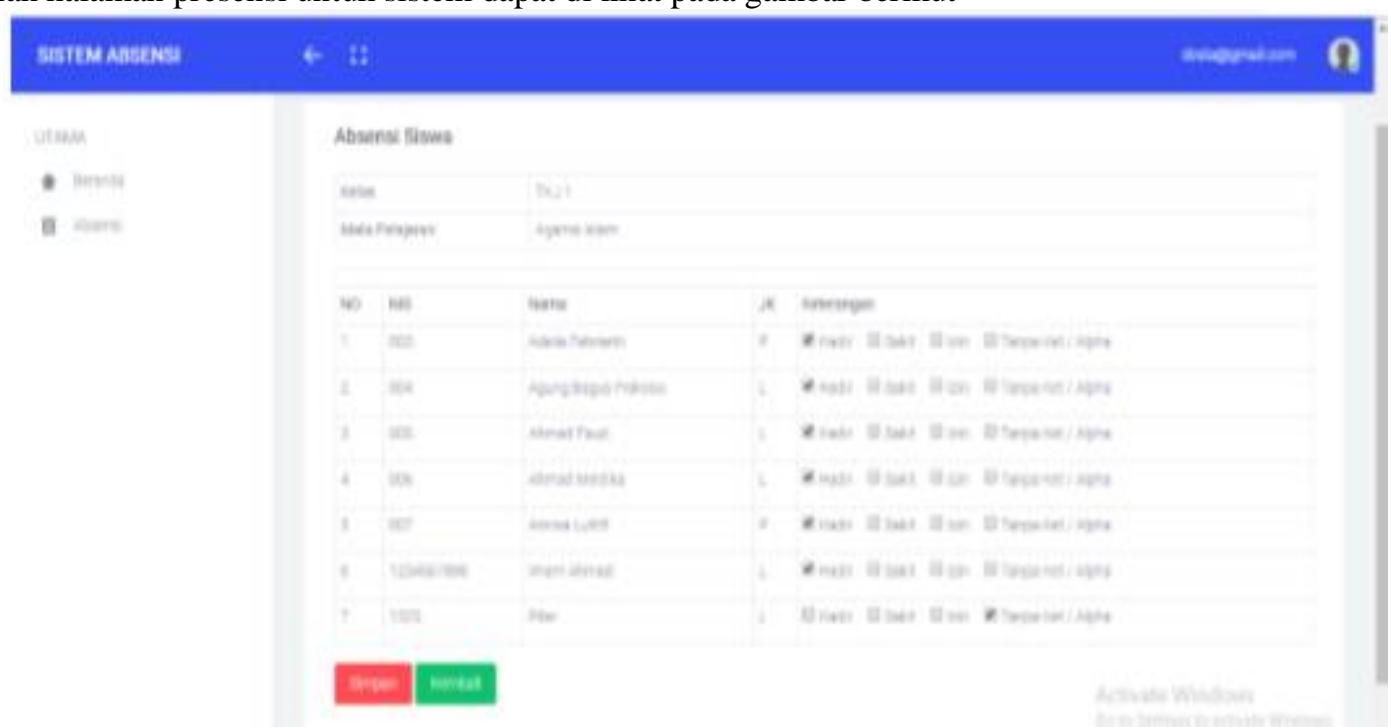

\section{Gambar 5. Halaman Presensi}

\section{Pengenalan SMS Gateway}

Tampilan halaman SMS Gateway untuk sistem dapat di lihat pada gambar berikut 


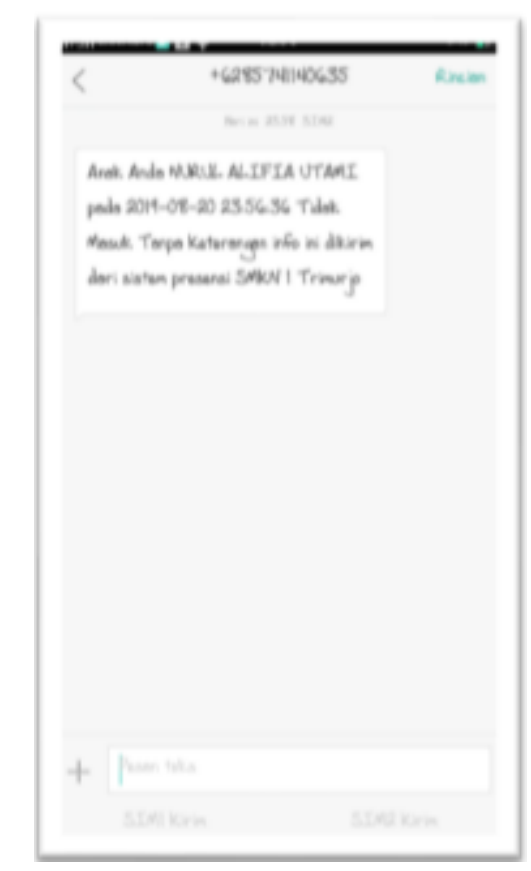

Gambar 6. SMS Gateway

Bagaimana merancang serta membangun aplikasi presensi SMS gateway berbasis web yang dapat memberikan informasi presensi kepada orang tua siswa-siswi pada SMKN 1 Trimurjo?

Pembuatan aplikasi ini menggunakan metode ekstreme programming yang melalui beberapa tahap. Tahapan pertama perencanaan yaitu memahami konteks bisnis, mendefinisikan keluaran (output) dari aplikasi, fitur pada aplikasi, penentuan waktu dan biaya aplikasi, dan alur pengembangan aplikasi (Suryono dkk, 2018). Tahapan kedua desain yaitu mendesain aplikasi secara sederhana menggunakan kartu CRC (Class Responsibility Collaborator). Tahapan ketiga implementasi yaitu melakukan pembuatan coding program menggunakan bahasa bahasa pemrograman PHP framework codeigniter. Tahapan keempat pengujian sistem aplikasi presensi SMS Gateway ini menggunakan pengujian blackbox testing.

\section{HASIL PENGUJIAN}

Pengujian ini dilakukan oleh beberapa sample yang terdiri dari 2 orang dosen, 10 orang guru, 1 kepala sekolah, dan 1 tata usaha yang dipilih secara acak untuk mewakili keseluruhan pengujian pada sistem presensi SMS gateway berbasis web ini.

Tabel 1. Hasil Pengujian BlackBox Dosen

\begin{tabular}{|l|l|l|l|}
\hline Kategori & Frekuensi Jawaban & Responden & Total Pertanyaan \\
\hline Diterima & $\mathbf{7 2}$ & $\mathbf{2}$ & $\mathbf{7 2}$ \\
\hline Ditolak & $\mathbf{3}$ & $\mathbf{2}$ & $\mathbf{6 9}$ \\
\hline
\end{tabular}

Rumus Perhitungan Pengujian

$$
\begin{gathered}
\frac{\text { Jumlah Pertanyaan Diterima }}{\text { Total Pertanyaan Diajukan }}=x 100 \% \\
\frac{69}{72} \times 100 \%=96 \%
\end{gathered}
$$


Tabel 2. Hasil Pengujian BlackBox Guru

\begin{tabular}{|l|l|l|l|}
\hline Kategori & Frekuensi Jawaban & Responden & Total Pertanyaan \\
\hline Diterima & $\mathbf{1 1}$ & $\mathbf{1 0}$ & $\mathbf{1 1}$ \\
\hline Ditolak & $\mathbf{0}$ & $\mathbf{1 0}$ & $\mathbf{1 1}$ \\
\hline
\end{tabular}

Rumus Perhitungan Pengujian

$$
\begin{gathered}
\frac{\text { Jumlah Pertanyaan Diterima }}{\text { Total Pertanyaan Diajukan }}=x 100 \% \\
\frac{11}{11} \times 100 \%=100 \%
\end{gathered}
$$

Tabel 3. Hasil Pengujian BlackBox Kepala Sekolah

\begin{tabular}{|l|l|l|l|}
\hline Kategori & Frekuensi Jawaban & Responden & Total Pertanyaan \\
\hline Diterima & $\mathbf{8}$ & $\mathbf{1}$ & $\mathbf{8}$ \\
\hline Ditolak & $\mathbf{0}$ & $\mathbf{1}$ & $\mathbf{8}$ \\
\hline
\end{tabular}

Rumus Perhitungan Pengujian

$$
\begin{aligned}
& \frac{\text { Jumlah Pertanyaan Diterima }}{\text { Total Pertanyaan Diajukan }}=x 100 \% \\
& \qquad \frac{8}{8} \times 100 \%=100 \%
\end{aligned}
$$

Tabel 4. Hasil Pengujian BlackBox Tata Usaha

\begin{tabular}{|l|l|l|l|}
\hline Kategori & Frekuensi Jawaban & Responden & Total Pertanyaan \\
\hline Diterima & 51 & 1 & 53 \\
\hline Ditolak & $\mathbf{1}$ & 1 & 53 \\
\hline
\end{tabular}

Rumus Perhitungan Pengujian

$$
\begin{gathered}
\frac{\text { Jumlah Pertanyaan Diterima }}{\text { Total Pertanyaan Diajukan }}=x 100 \% \\
\frac{53}{53} \times 100 \%=100 \%
\end{gathered}
$$

Setelah dilakukan perhitungan maka diperoleh sebuah hasil dari perhitungan beberapa responden. Dosen mendapatkan hasil 96\%, guru mendapatkan hasil 100\%, kepala sekolah mendapatkan hasil 100\%, tata usaha mendapatkan hasil $100 \%$. Maka diperoleh kesimpulan rata - rata hasil perhitungan dari beberapa responden yang telah melakukan pengujian mendapatkan hasil $99 \%$ yang artinya sistem yang penulis implementasikan layak untuk digunakan oleh SMKN 1 Trimurjo.

\section{SIMPULAN}

Berdasarkan hasil penelitian yang telah dilakukan, maka kesimpulan penelitian yang berjudul Rancang Bangun Aplikasi Presensi SMSGateway Berbasis Web Dengan Framework Codeigniter Pada Smkn 1 Trimurjo, yaitu: 
1. Aplikasi Presensi SMS Gateway dibuat dengan menggunakan permodelan berorientasi objek yaitu menggunakan Usecase diagram, activity diagram, class diagram, serta CRC Card, sehingga mempermudah dalam perancangan aplikasi yang akan dibuat.

2. Mengimplementasikan teknologi SMS gateway dengan menggunakan framework codeigniter serta pengujian menggunakan blackbox testing dengan hasil yaitu 99\% dari seluruh responden yang telah memberikan jawaban dari aplikasi yang telah diuji.

\section{UCAPAN TERIMA KASIH}

Puji syukur penulis panjatkan kepada Allah SWT, karena atas berkat dan rahrnat-Nya, penulis dapat menyelesaikan Penelitian dengan judul "Rancang Bangun Aplikasi Presensi SMSGateway Berbasis Web Dengan Framework Codeigniter Pada Smkn 1 Trimurjo".

1. Bapak Dr. H.M. Nasrullah Yusuf, S.E., M.B.A. selaku Rektor Universitas Teknokrat Indonesia.

2. Bapak Dr. H. Mahathir Muhammad, S.E., M.M. selaku Dekan Fakultas Teknik dan Ilmu Komputer Universitas Teknokrat Indonesia.

3. Ibu Dyah Ayu Megawaty, M.Kom., selaku Ketua Program Studi S1 Informatika Fakultas Teknik dan Ilmu Komputer Universitas Teknokrat Indonesia.

\section{REFERENSI/DAFTAR PUSTAKA}

Ahmad, I., Indra, H., 2016. Rancang Bangun Sistem Tiket Masuk Pada Objek Wisata Pantai Mutun. Jurnal Rekayasa Dan Manajemen Sistem Informasi, 2(2).

Budiman, H. 2017. 'Peran Teknologi Informasi dan Komunikasi dalam Pendidikan', Jurnal Pendidikan Agama, 8(1), pp. 3143.

Damayanti, Sulistiani, H., 2017. Sistem Informasi Pembayaran Biaya Sekolah Pada SD Ar-Raudah Bandar Lampung. Jurnal TEKNOINFO, 11(2).

Dendi Ramdani, Partono, C. S. 2014. 'Pengembangan Aplikasi Presensi di PT. INTI Bandung Berbasis Desktop Application', Jurnal Algoritma Sekolah Tinggi Teknologi Garut, 11(1), pp. 1-7.

Fauziah, Y. 2013. Aplikasi Iklan Baris Online menggunakan Arsitektur REST Web Service. Jurnal Telematika, 9(2).

Martono, A., Setyawan, E. A. (2018) 'Implementasi Sistem Informasi Kehadiran Siswa Pada SMKN 2 Kabupaten Tangerang'.

Mira Afrina, A. I. (2015) 'Pengembangan Sistem Informasi SMS Gateway Dalam Meningkatkan Layanan Komunikasi Sekitar Akademika Fakultas Ilmu Komputer Unsri', Jurnal Sistem Informasi, 7(2).

Rulyana, D., Borman, R.I., 2014. Aplikasi Simulasi Tes Potensi Akademik Berbasis Mobile Platform Android. In Seminar Nasional FMIPA-Universitas Terbuka. DKI Jakarta, 2014.

Suryono, R. R., Darwis, D., Gunawan, S. I. 2018. Audit Tata Kelola Teknologi Informasi Menggunakan Framework Cobit 5 (Studi Kasus: Balai Besar Perikanan Budidaya Laut Lampung). Jurnal Teknoinfo, 2018

Untung Rahardja, U., Aini, Q. S. 2018. Pengintegrasian YII Framework Berbasis API pada Sistem Penilaian Absensi. Jurnal Ilmiah SISFOTENIKA, 8(2). 